\title{
Visible light-driven and chloroperoxidase-catalyzed oxygenation reactions $\dagger$
}

\author{
Received (in Cambridge, UK) 27th July 2009, Accepted 14th September 2009 \\ First published as an Advance Article on the web 1st October 2009 \\ DOI: $10.1039 / b 915078 a$
}

Daniel I. Perez, $\ddagger$ Maria Mifsud Grau, $\ddagger$ Isabel W. C. E. Arends* and Frank Hollmann*

Robust peroxidase-catalyzed enantiospecific oxyfunctionalizations can be achieved by simple light-driven in situ generation of hydrogen peroxide.

Chloroperoxidase from Caldariomyces fumago (CPO, E.C. 1.11.1.10) is a versatile oxidation and oxyfunctionalization catalyst. ${ }^{1}$ It catalyzes a broad range of synthetically useful transformations such as oxidation of alcohols, ${ }^{2}$ hydroxylation of allylic, propargylic and benzylic $\mathrm{C}-\mathrm{H}$ bonds, ${ }^{3} \mathrm{C}=\mathrm{C}$ double bond epoxidations, ${ }^{4}$ halohydroxylations, ${ }^{5}$ and heteroatom oxygenation reactions. ${ }^{6}$ Many of these proceed with high to exclusive regio-, chemo-, and enantioselectivity. Unlike the related P450 monooxygenases, ${ }^{7}$ CPO does not rely on prohibitively expensive nicotinamide cofactors and molecular oxygen to regenerate its catalytically active oxyferryl heme active site. ${ }^{1 b}$ Instead, CPO utilizes simple hydrogen peroxide, which makes CPO an attractive catalyst for preparative organic chemistry.

Its high synthetic potential however is impaired by its rather poor operational stability, particularly towards $\mathrm{H}_{2} \mathrm{O}_{2}{ }^{8}{ }^{8}$ The exact inactivation mechanism is still under debate but it is clear that oxidative degradation of the heme prosthetic group plays a major role. ${ }^{9}$ Portionwise addition of $\mathrm{H}_{2} \mathrm{O}_{2}{ }^{10,11}$ to maintain the $\mathrm{H}_{2} \mathrm{O}_{2}$ concentration at acceptable levels significantly increased the total turnover number (TTN) of CPO over stoichiometric use of $\mathrm{H}_{2} \mathrm{O}_{2}$ or less reactive organic peroxides. $^{3 a, 12}$ But the heterogeneous nature of the external addition results in 'hot spots' comprising locally high $\mathrm{H}_{2} \mathrm{O}_{2}$ concentrations and fast CPO inactivation. ${ }^{6 b}$ This may be circumvented by generating $\mathrm{H}_{2} \mathrm{O}_{2}$ in homogeneous phase (in situ) by reduction of molecular oxygen. Chemical, ${ }^{13}$ electrochemical, ${ }^{6 c, 14}$ or enzymatic methods have been reported. ${ }^{6 b, 15,16}$ But each approach comprises specific disadvantages such as need for specialized equipment or a second, costly enzyme. Furthermore, sufficiently high TTNs have not been achieved yet for CPO. Consequently, the quest for a simple, easily applicable, and robust in situ $\mathrm{H}_{2} \mathrm{O}_{2}$-generation method continues.

Here, we report on a novel, light-driven approach for the in situ generation of $\mathrm{H}_{2} \mathrm{O}_{2}$ to promote CPO-catalyzed oxidation-oxyfunctionalization reactions. We make use of (1) facile reduction of visible light-excited isoalloxazines

Department of Biotechnology, Biocatalysis and Organic Chemistry, Delft University of Technology, Julianalaan 136, Delft, 2628 BL, The Netherlands.E-mail: f.hollmann@tudelft.nl,i.w.c.e.arends@tudelft.nl; Fax: + 31 (0)152781415; Tel: + 31 (0)1522781957

$\dagger$ Electronic supplementary information (ESI) available: Mechanistic details, experimental setup. See DOI: 10.1039/b915078a

$\ddagger$ These authors contributed equally.

(e.g. flavine adenine dinucleotide FAD, -mononucleotide FMN, or riboflavin Rf) by simple and cheap sacrificial electron donors such as ethylenediaminetetraacetate (EDTA), (2) high reactivity of reduced flavins $\left(\mathrm{FADH}_{2}, \mathrm{FMNH}_{2}, \mathrm{RfH}_{2}\right)$ with $\mathrm{O}_{2}$ yielding $\mathrm{H}_{2} \mathrm{O}_{2}$ (ESI $\left.\dagger\right) .{ }^{17}$ We hypothesized that the reaction sequence outlined in Scheme 1 might be useful to promote CPO-catalysis.

As a starting point for our light-driven in situ $\mathrm{H}_{2} \mathrm{O}_{2}$ generation system we (arbitrarily) chose FMN as photocatalyst and EDTA as sacrificial electron donor. An ordinary slide projector equipped with a $250 \mathrm{~W}$ bulb (Philips 7748 XHP, see $\mathrm{ESI} \dagger$ for experimental setup) served as light-source. Illumination of an anaerobic solution of FMN $(0.1 \mathrm{mM}$ in potassium phosphate buffer $\left(\mathrm{KP}_{\mathrm{i}}\right) \mathrm{pH}$ 5.1) in the presence of EDTA resulted in fast $(<1$ minute) decolourization of the solution indicating full reduction of FMN. The characteristic yellow colour of oxidized FMN returned upon aeration accompanied by the formation of $\mathrm{H}_{2} \mathrm{O}_{2}$. This sequence could be repeated several times. From these experiments we estimated a catalytic performance for the flavin photocatalyst (TF) of approximately 1.6 turnovers per minute.

Next we combined the photocatalytic $\mathrm{H}_{2} \mathrm{O}_{2}$ generation with $\mathrm{CPO}$ to perform a range of typical CPO-oxidation and -oxyfunctionalization reactions (Table 1).

In all cases, the photoenzymatic approach turned out to be superior to the stoichiometric addition of $\mathrm{H}_{2} \mathrm{O}_{2}$ which we attribute to an increased stability of CPO (vide infra). Performing these experiments either in the absence of EDTA, FMN, or in darkness yielded no conversion. Also in the absence of CPO, no conversion was observed with the exception of thioanisole where trace amounts of racemic sulfoxide were found. The enantioselectivity of the CPO-catalyzed sulfoxidation reaction was not impaired (Table 1).

The system is not confined to FMN as photocatalyst: substituting FMN by FAD or Rf under otherwise identical conditions influenced neither rate nor the stereochemical outcome of the sulfoxidation reaction (data not shown).

Encouraged by these results, we further evaluated the possibility to control the $\mathrm{H}_{2} \mathrm{O}_{2}$ formation rate via the photocatalyst concentration (Fig. 1). The overall rate correlated with the flavin concentration applied. Thus, the sulfoxide formation rate increased from $2.3 \mathrm{mM} \mathrm{h}^{-1}$ to $11.8 \mathrm{mM} \mathrm{h}^{-1}$ with increase of [FMN] from $10 \mu \mathrm{M}$ to $250 \mu \mathrm{M}$. In terms of $\mathrm{TF}(\mathrm{CPO})$ this corresponds to an increase from $9.8 \mathrm{~min}^{-1}$ to $123 \mathrm{~min}^{-1}$. Furthermore, significant accumulation of $\mathrm{H}_{2} \mathrm{O}_{2}$ was not observed. This indicates that the photocatalytic generation of $\mathrm{H}_{2} \mathrm{O}_{2}$ was overall rate-limiting and $\mathrm{H}_{2} \mathrm{O}_{2}$ was quickly consumed by CPO-catalyzed sulfoxidation. The very low in situ $\mathrm{H}_{2} \mathrm{O}_{2}$ concentration also explains the significantly 


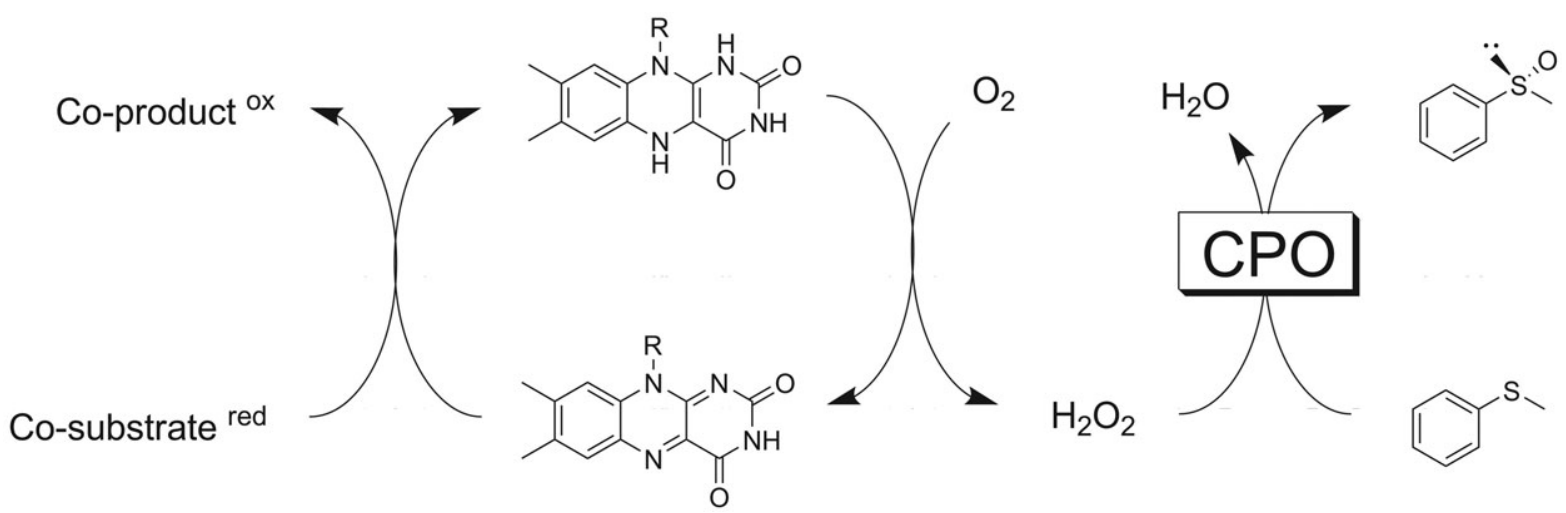

Scheme 1 Light-driven in situ $\mathrm{H}_{2} \mathrm{O}_{2}$ generation to promote CPO-catalyzed sulfoxidation reactions. Co-substrates used in this study comprise EDTA and formate (see ESI $\dagger$ ).

Table 1 Typical CPO-catalyzed oxidation-oxyfunctionalization reactions driven by the proposed photochemical in situ $\mathrm{H}_{2} \mathrm{O}_{2}$ generation approach compared to the stoichiometric use of $\mathrm{H}_{2} \mathrm{O}_{2}{ }^{a}$

\begin{tabular}{lll}
\hline & \multicolumn{2}{l}{ Conversion (\%)/TN (CPO) } \\
\cline { 2 - 3 } & Product & \multicolumn{2}{l}{ FMN $/ h \nu / \mathrm{O}_{2}$} \\
\hline
\end{tabular}

${ }^{a}$ Conditions: [thioanisole] $=8 \mathrm{mM},[\mathrm{CPO}]=0.357 \mu \mathrm{M},\left[\mathrm{H}_{2} \mathrm{O}_{2}\right]=8 \mathrm{mM}$ or $[$ EDTA $]=8 \mathrm{mM},[\mathrm{FMN}]=80 \mu \mathrm{M}, h \nu$, both methods yielded $(R)$-sulfoxide in optical purity $>99 \%$ ee; [indole $]=[$ furfuryl alcohol $]=$ $25 \mathrm{mM},[\mathrm{CPO}]=7.85 \mu \mathrm{M},\left[\mathrm{H}_{2} \mathrm{O}_{2}\right]=25 \mathrm{mM}$ or $[$ EDTA $]=25 \mathrm{mM}$, $[\mathrm{FMN}]=250 \mu \mathrm{M}, h \nu$; no over oxidation products such as sulfone or furfurylic acid were observed. $\mathrm{TN}=$ turnover number $=$ $\operatorname{mol}($ product $) \times \operatorname{mol}(\mathrm{CPO})^{-1}$.

increased operational stability of CPO: while with stoichiometric $\mathrm{H}_{2} \mathrm{O}_{2}$, CPO was fully inactivated within maximally 3 minutes, stable production of (enantiopure) sulfoxide continued for at least $7 \mathrm{~h}$ in case of the photocatalytic in situ formation of $\mathrm{H}_{2} \mathrm{O}_{2}$ corresponding to an at least 100-fold improved operational stability of CPO. Thus, we were able to demonstrate that the $\mathrm{H}_{2} \mathrm{O}_{2}$ supply rate can easily be controlled via the photocatalyst concentration.

Envisaging an environmentally benign photoenzymatic reaction, EDTA may not be the sacrificial electron donor of choice. Especially the generation of formaldehyde and ethylene diamine as waste products is not desirable from an environmental and toxicological point-of-view. ${ }^{18}$ Other sacrificial electron donors such as methionine, adrenaline, or nicotine $^{17 a}$ are also not attractive as again significant amounts of waste are generated. Therefore, we evaluated the suitability of formate as simple and cheap sacrificial electron donor, yielding $\mathrm{CO}_{2}$ as the sole by-product. In fact, EDTA could be substituted by formate as sacrificial electron donor to promote CPO-catalyzed sulfoxidation and full conversion was observed $(\mathrm{ESI} \dagger)$. Interestingly, here the enantioselectivity was somewhat

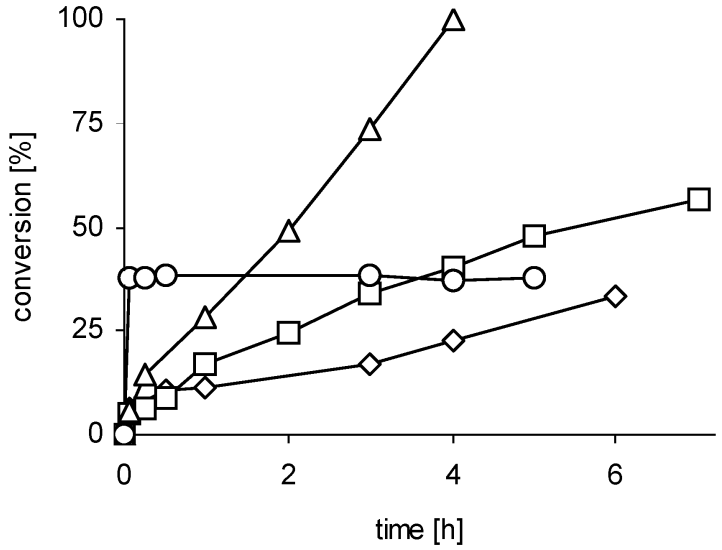

Fig. 1 Influence of FMN concentration on the light-driven CPOcatalyzed oxidation of thioanisole. Conditions: $25 \mathrm{~mL}{ }^{t} \mathrm{BuOH}-50 \mathrm{mM}$ phosphate buffer $\mathrm{pH}=5.1(25 / 75), T=25^{\circ} \mathrm{C}$, [thioanisole] $=50 \mathrm{mM}$, $[\mathrm{CPO}]=3.93 \mu \mathrm{M}$, oxidant: $\left[\mathrm{H}_{2} \mathrm{O}_{2}\right]=50 \mathrm{mM}(\mathrm{O})$ or $[$ EDTA $]=$ $50 \mathrm{mM},[\mathrm{FMN}]=10 \mu \mathrm{M}(\diamond), 50 \mu \mathrm{M}(\square), 250 \mu \mathrm{M}(\triangle)$. In all samples, the enantiomeric purity of the sulfoxide was greater than $98 \%$ ee.

lower $(78 \%$ ee, $R$ ) than using EDTA as the sacrificial electron donor ( $>99 \%$ ee, $R$ ). This reduction of enantioselectivity was even more pronounced if $\mathrm{H}_{2} \mathrm{O}_{2}$ was added stoichiometrically $(\mathrm{ESI} \dagger)$. Similar effects have been reported recently for the CPO-catalyzed epoxidation of limonene $e^{4 d}$ and can be rationalized by assuming binding of formate to the heme-iron as suggested by crystallographic data. ${ }^{19}$ Thus, presence of formate might impair precise positioning of thioanisole within the $\mathrm{CPO}$ active site.

Overall, we have demonstrated that the proposed lightdriven approach for in situ generation of $\mathrm{H}_{2} \mathrm{O}_{2}$ is practicable to promote CPO-catalyzed oxygenation reactions. The $\mathrm{H}_{2} \mathrm{O}_{2}$ generation rate can be easily controlled via the photocatalyst concentration. Further characterization will result in an optimized ratio of photo- and biocatalyst enabling high reaction rates while minimizing $\mathrm{H}_{2} \mathrm{O}_{2}$-related inactivation of the enzyme. Thus, we have turned a previously undesired side reaction ${ }^{17 c, d}$ into a simple, robust, and easily applicable novel method for peroxidase-catalyzed oxidation and oxyfunctionalization reactions. Compared to established approaches (Table 2), one major advantage of the photocatalytic generation of 
Table 2 CPO-catalyzed sulfoxidation of thioanisole using different $\mathrm{H}_{2} \mathrm{O}_{2}$ generation/dosage methods

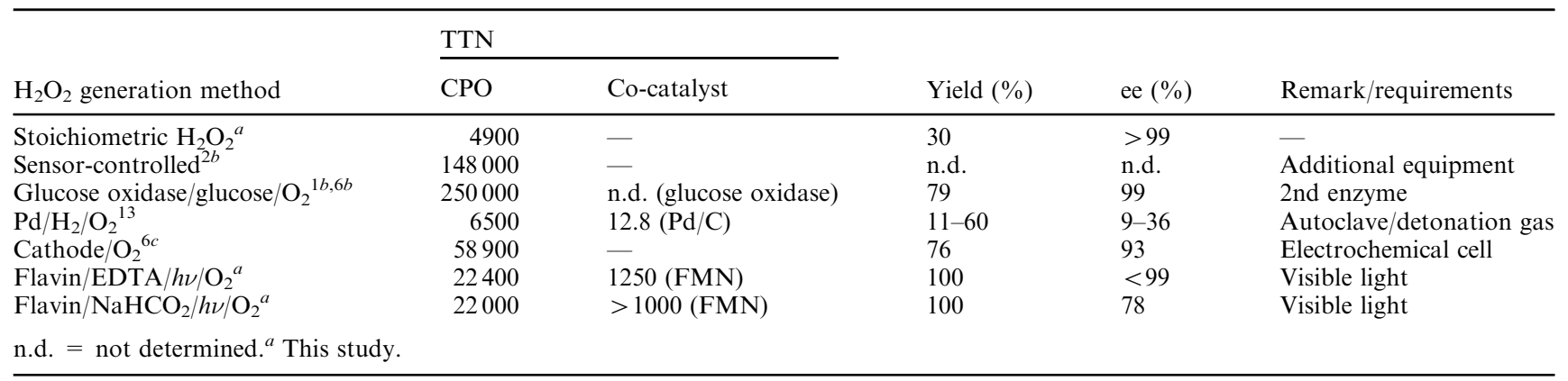

$\mathrm{H}_{2} \mathrm{O}_{2}$ lies in its simplicity. No specialized equipment or catalysts are required, all reactions were performed at ambient pressure and temperature using a readily available light-source (also sunlight) and commercially available catalysts. Furthermore, already under non-optimized conditions turnover numbers of more than 1.000 and 22.000 have been achieved for the photocatalyst and CPO, respectively. Current work ongoing in our laboratory comprises full characterization and optimization of the reaction setup and evaluation of further simple sacrificial electron donors e.g. phosphite. Thus, we are convinced to eventually obtain a simple, compatible, and environmentally benign reaction setup. Furthermore, preliminary results suggest a general applicability to heme enzyme-catalyzed oxidation reactions such as horseradish peroxidase-catalyzed oxidative $\mathrm{C}-\mathrm{C}$ coupling reactions and cytochrome $\mathrm{C}$-catalyzed oxygenations. Also this approach might be used for simplified P450 oxygenation reactions via the hydrogen peroxide shunt pathway $^{20}$ and thereby become useful e.g. for screening and drug metabolite synthesis.

\section{Notes and references}

1 (a) D. J. Leak, R. A. Sheldon, J. M. Woodley and P. Adlercreutz, Biocatal. Biotransform., 2009, 27, 1; (b) F. van Rantwijk and R. A. Sheldon, Curr. Opin. Biotechnol., 2000, 11, 554; (c) M. P. J. van Deurzen, F. van Rantwijk and R. A. Sheldon, Tetrahedron, 1997, 53, 13183; (d) V. M. Dembitsky, Tetrahedron, 2003, 59, 4701; (e) M. Hofrichter and R. Ullrich, Appl. Microbiol. Biotechnol., 2006, 71, 276.

2 (a) S. Hu and J. S. Dordick, J. Am. Chem. Soc., 2002, 67, 314; (b) M. P. J. van Deurzen, F. van Rantwijk and R. A. Sheldon, J. Carbohydr. Res., 1997, 16, 299; (c) E. Kiljunen and L. T. Kanerva, Tetrahedron: Asymmetry, 1999, 10, 3529.

3 (a) J.-B. Park and D. S. Clark, Biotechnol. Bioeng., 2006, 94, 189; (b) S. Hu and L. P. Hager, Biochem. Biophys. Res. Commun., 1998, 253, 544; (c) V. P. Miller, R. A. Tschirretguth and P. R. O. Demontellano, Arch. Biochem. Biophys., 1995, 319, 333; (d) D. J. Bougioukou and I. Smonou, Tetrahedron Lett., 2002, 43, 339; (e) S. Hu and L. P. Hager, J. Am. Chem. Soc., 1999, 121, 872; $(f)$ M. P. J. Van Deurzen, K. Seelbach, F. van Rantwijk, U. Kragl and R. A. Sheldon, Biocatal. Biotransform., 1997, 15, 1; (g) R. L. Osborne, G. M. Raner, L. P. Hager and J. H. Dawson, J. Am. Chem. Soc., 2006, 128, 1036.

4 (a) A. F. Dexter, F. J. Lakner, R. A. Campbell and L. P. Hager, J. Am. Chem. Soc., 1995, 117, 6412; (b) A. Zaks and D. R. Dodds,
J. Am. Chem. Soc., 1995, 117, 10419; (c) E. J. Allain, L. P. Hager, L. Deng and E. N. Jacobsen, J. Am. Chem. Soc., 1993, 115, 4415; (d) S. Águila, R. Vazquez-Duhalt, R. Tinoco, M. Rivera, G. Pecchi and J. B. Alderete, Green Chem., 2008, 10, 647; (e) L. P. Hager, F. J. Lakner and A. Basavapathruni, J. Mol. Catal. B: Enzym., $1998,5,95$.

5 B. A. Kaup, U. Piantini, M. Wust and J. Schrader, Appl. Microbiol. Biotechnol., 2007, 73, 1087.

6 (a) S. Colonna, N. Gaggero, A. Manfredi, L. Casella and M. Gullotti, J. Chem. Soc., Chem. Commun., 1988, 1451; (b) F. van de Velde, N. D. Lourenço, M. Bakker, F. van Rantwijk and R. A. Sheldon, Biotechnol. Bioeng., 2000, 69, 286; (c) C. Kohlmann and S. Lütz, Eng. Life Sci., 2006, 6, 170; (d) V. Trevisan, M. Signoretto, S. Colonna, V. Pironti and G. Strukul, Angew. Chem., Int. Ed., 2004, 43, 4097; (e) S. Colonna, N. Gaggero, L. Casella, G. Carrea and P. Pasta, Tetrahedron: Asymmetry, 1992, 3, 95 .

7 (a) V. B. Urlacher and R. D. Schmid, Curr. Opin. Biotechnol., 2002, 13, 557; (b) V. B. Urlacher and S. Eiben, Trends Biotechnol., 2006, 24, 324 .

8 A. N. Shevelkova and A. D. Ryabov, Biochem. Mol. Biol. Int., 1996, 39, 665 .

9 (a) B. Valderrama, M. Ayala and R. Vazquez-Duhalt, Chem. Biol., 2002, 9, 555; (b) J.-B. Park and D. S. Clark, Biotechnol. Bioeng., 2006, 93, 1190; (c) C. E. Grey, M. Hedström and P. Adlercreutz, ChemBioChem, 2007, 8, 1055.

10 J. H. Dawson and M. Sono, J. Am. Chem. Soc., 1987, 87, 1255.

11 K. Seelbach, M. P. J. van Deurzen, F. van Rantwijk, R. A. Sheldon and U. Kragl, Biotechnol. Bioeng., 1997, 55, 283.

12 B. K. Samra, M. Andersson and P. Adlercreutz, Biocatal. Biotransform., 1999, 17, 381.

13 S. K. Karmee, C. Roosen, C. Kohlmann, S. Lütz, L. Greiner and W. Leitner, Green Chem., 2009, 11, 1052.

14 C. E. La Rotta, E. D'Elia and E. P. S. Bon, Electron. J. Biotechnol., 2007, 10, 24.

15 S. Neidleman, F. William and J. Geigert, US Pat., 4284723 , 1981.

16 H. Uyama, H. Kurioka and S. Kobayashi, Polym. J. (Tokyo), 1997, 29, 190.

17 (a) W. R. Frisell, C. W. Chung and C. G. Mackenzie, J. Biol. Chem., 1959, 234, 1297; (b) V. Massey, M. Stankovich and P. Hemmerich, Biochemistry, 1978, 17, 1; (c) F. Hollmann, A. Taglieber, F. Schulz and M. T. Reetz, Angew. Chem., Int Ed., 2007, 46, 2903; (d) A. Taglieber, F. Schulz, F. Hollmann, M. Rusek and M. T. Reetz, ChemBioChem, 2008, 9, 565.

18 R. A. Sheldon, Chem. Commun., 2008, 3352.

19 K. Kuhnel, W. Blankenfeldt, J. Terner and I. Schlichting, J. Biol. Chem., 2006, 281, 23990.

20 H. Joo, Z. L. Lin and F. H. Arnold, Nature, 1999, 6737, 670. 